\title{
CORRESPONDENCE
}

\section{UK coalition's funding plan accelerates trends Labour started}

You seem to view the UK coalition government's approach to funding research in universities as a change of direction, even harking back to that of the 1980s (Nature 466, $296 ; 2010)$. This is not the case.

The emphasis on economic returns by minister David Willetts is couched in language such as "absorptive capacity", which was part and parcel of the former Labour government's approach. For example, in addition to the paper by Jonathan Haskel and Gavin Wallis that you mention, Willetts cites one by Rachel Griffith and colleagues at London's Institute of Fiscal Studies, a mainstay of thinking on this for the Treasury under Labour (see go.nature. com/orVDfF). The significance of absorptive capacity is that it leads us away from pure excellence, as measured by the citation metrics you describe, and towards a concept of 'good-enough' science, which does just enough to improve a firm's absorptive capacity but not obviously anything more.

I thus believe it is more accurate to see the coalition government's approach as a potentially powerful acceleration of the trends instigated under Labour.

William Cullerne Bown Research Fortnight, 134-146 Curtain Road, London EC2A 3AR, UK e-mail:wocb@researchresearch.com

The long story of how the boson got only Higgs's name

In his review of my book Massive, Frank Close wonders how physicist Peter Higgs alone came to be associated with the elusive boson that bears his name (Nature 465, 873-874; 2010).

The story, as recalled by Higgs and by colleagues of the late Korean-born physicist Benjamin Lee, is as follows. Higgs discussed his work on what became known as the Higgs mechanism with Lee over a glass of wine at a conference reception in 1967. Higgs's famous 1964 paper had been the first to draw attention to the existence of the massive boson that would become the signature particle of the mass-giving mechanism. In his discussion with Lee, Higgs did not enter into a full history of those on whose work he had built, given the informal nature of their chat.

Fast-forward to 1972, when Lee was rapporteur for the
International Conference on High-Energy Physics at the National Accelerator Laboratory (now Fermilab) in Batavia, Illinois. Recalling their earlier conversation, he used Higgs's name as a shorthand to describe work based on his kind of theory. From there, the name stuck and the Higgs boson was born.

Higgs openly acknowledges the contributions of others in this defining work. He opened one conference by suggesting that the Higgs mechanism should be renamed the "ABEGHHK'tH mechanism" after all of the people (Phil Anderson, Robert Brout, Francois Englert, Gerry Guralnik, Dick Hagen, Peter Higgs, Tom Kibble and Gerard 't Hooft) who discovered it, or rediscovered it.

Ian Sample 31 Elm Park, London SW2 2TX, UK

e-mail: ian.sample@guardian.co.uk 